\title{
Heredity in Plants, Animals, and Man.
}

\author{
Being the Presidential Address detivered before the \\ Plymouth Institution, October 12th, 1916.
}

By

E. J. Allen, D.Sc., F.R.S.,

Director of the Plymouth Laboratory.

[Reprinted from the Transactions of the Plymouth Institution.]

With Diagrams 1-11 in the Text.

OF the many branches of biological enquiry which have occupied the attention of naturalists during the last twenty years the one which has perhaps yielded the most striking results, from a theoretical point of view, has been the study of heredity in plants and animals - the study of the laws according to which the characters of parents are transmitted to their descendants.

The practical achievements of the farmer, the gardener, and the animal breeder in obtaining and fixing innumerable varieties of cultivated plants and domesticated animals had made everyone familiar with the general facts that variations occur, and that these variations sometimes are and sometimes are not transmitted from parent to offspring. Common observation of the men, women, and children with whom we come in contact shows us that human beings also exhibit similar phenomena. Amongst a family of children several quite distinct types of feature, of build, of colour of hair or eye are found, and it is often quite plain from which parent, or from the family of which parent, a particular characteristic has been derived. The same thing is sometimes clearly true of mental and moral traits.

Charles Darwin, especially in his work " On the Variations of Animals and Plants under Domestication," brought together a great collection of facts bearing on this subject, which formed the basis upon which his theory of natural selection was built up. Around the question of the cause or origin of such variations much discussion has centred. Darwin himself was inclined to favour the view generally associated with the 
name of Lamarck, that variations were brought about by the direct action of the environment - of the conditions under which the life of the animal or plant was carried on - and that variations originating in this way were capable of being inherited. Changes of structure brought about by the use or disuse of organs were considered of particular importance in this connection. Especially when the environmental conditions had remained the same for many generations did the characters produced by them become, it was thought, permanently fixed in the species as part of its hereditary constitution. This view was strongly attacked by Weismann, who held that variations produced by external conditions, and especially by use and disuse of parts, were not hereditary, and the characters of the germ plasm as received from the parents were transmitted to the offspring without change. Weismann's view has been considered the more probable by the majority of biologists since he wrote, though by a minority it has always been subjected to vigorous criticism.

With the question of the causes that give rise to variations capable of being inherited, it is not however my intention to deal to-night. Accept ing the fact, which cannot be disputed, that such variations do occur, and recognising that characters of the parent sometimes do and sometimes do not appear in the offspring, when parents with different characters are mated together, we shall consider the system or law in accordance with which the hereditary transmission of characters takes place.

What is now recognised as the epoch-making pioneer work in this subject was carried out by Gregor Mendel, Abbot of Brünn, a small town in Austria, and published by him in the Proceedings of the local natural history society at Brün in 1865. This work unfortunately escaped attention for many years, and it was not until 1900 that the importance of Mendel's paper was recognised by de Vries, Correns and Tschermak, who all three about the same time brought it into notice. The work has since been repeated and extended by Bateson, Punnett and many other workers in this country, on the Continent, and in America, and to-day there is a very extensive literature dealing with heredity on Mendelian principles in plants, animals, and man.

Mendel chose the common garden pea for the purposes of his experiments, a plant which exists in a number of well-marked varieties, capable of being crossed easily one with the other. The nature of his experiments and the character of the results which he obtained will perhaps be made clear by the description of a simple example. There is one variety of the pea plant that produces seeds, which when the pods are fully ripe and dry are of a uniform yellow colour. Another variety, on the other hand, produces peas which when they are ripe and dry are green.

It will be well known to you that in order to produce a ripe seed, which 
shall be capable of germination and growth, the union is necessary of two elements which occur in the flower. These elements are the ovule, which lies at the base of the flower, and the pollen, which generally takes the form of a fine dust or powder, and is formed by the stamens. The pollen is the male element, the ovule the female element; both are single cells, and together with the corresponding elements in animals they are called by the general name of gametes. The union of the ovule and pollen, which results in the formation of the ripe seed, is known as fertilisation. The general term applied to the ripe seed, the adult plant or the adult animal, which results from the union of the male and female gametes, is zygotethat which is yoked together. Two gametes or germ cells unite to form a zygote.

If plants of the variety which produces yellow peas are fertilised with the pollen from their own flowers or from flowers of the same variety, the seeds produced will all be yellow in colour, exactly resembling the parents. The variety breeds true to colour, and for however many generations the breeding is continued the colour remains the same, provided both parents in every case belong to the same variety.

Similarly the green-coloured variety, when the flowers are fertilised with their own pollen or with that from similar plants, produces pods which contain only green-coloured peas.

What Mendel did was to cross one of these varieties with the other. The ovules of a plant normally producing yellow-coloured peas were fertilised with pollen from a plant which produced green-coloured peas, or vice versâ. In this way a hybrid between the two varieties was obtained.

The hybrid peas resulting from this cross are all yellow in colour, and the result is the same whichever way the cross is made. The yellow colour is therefore said to be dominant to green, and green is said to be recessive.

This is illustrated in Diagram 1, in which the black discs represent yellow peas, the rings represent green peas.

The hybrid yellow seeds were then sown, and the resulting plants produced flowers. These flowers were allowed to fertilise themselvesthat is to say, the ovules were fertilised with pollen from the same flower, so that hybrid was mated with hybrid. The pods produced by these plants were found to contain both yellow and green peas. The recessive form - the green - therefore, which was lost in the first hybrid generation, appears again in the second generation.

As the result of a large number of experiments Mendel found that the proportion of yellow to green seeds amongst the offspring of the hybrids was $3: 1$, there were three times as many yellow as green. 
The seeds from this generation were collected and separately sown. The plants from the green seeds, when self-fertilised, produced all green seeds, and when these were again sown plants producing all green seeds again resulted. The pure recessive green variety had, therefore, com-

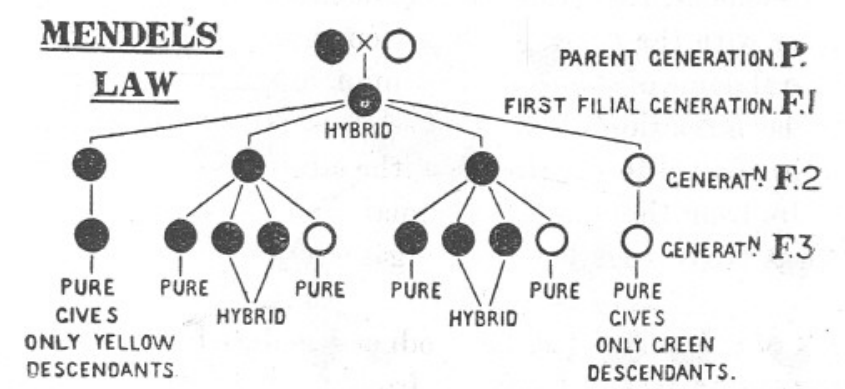

YELLOW AND GREEN PEAS. YELLOW IS DOMINANT. GREEN IS RECESSIVE.

FI, F.2, F.3, PLANTS WERE ALL SELF-FERTILISEO.

Diagram 1.

pletely segregated, or separated out from the hybrid, and the pure strain was completely recovered.

The yellow seeds, on the other hand, behaved differently. Two kinds of plants were produced, one kind which on self-fertilisation gave all yellow seeds, the other kind which gave both green and yellow, the two colours being in the proportion of three yellow to one green. There were twice as many plants which gave both green and yellow seeds as there were plants which gave only yellow. Peas from the kind which produced only yellow peas, when sown, produced plants which again gave all yellows, and this continued in succeeding generations. The pure dominant yellow variety, like the green recessive, had completely separated out and was re-established.

What happens will be clear from the diagram.

The fact that one of a pair of characters is dominant and the other recessive is not, however, a primary or essential feature of the scheme of Mendelian inheritance. When one character is dominant the hybrid has the appearance of the parent which bore that character, but in other cases the hybrid appears quite different from either parent. This is well illustrated by the case of the Andalusian Fowl figured in Diagram 2. The Blue Andalusian is a variety well known to the poultry fancier. It was known that the strain was not pure, and that when bred together the birds gave not only blues, but also some blacks and some splashed whites - a white with splashes of dark colour on the feathers. After the rediscovery of Mendel's work this case was investigated by Bateson and Punnett, 
who found that the blue bird was really a hybrid between the black and the splashed white. Both the blacks and the splashed whites are pure strains; blacks bred together give all blacks, whites bred together give all whites. When black is bred with white the birds obtained are all blue. The

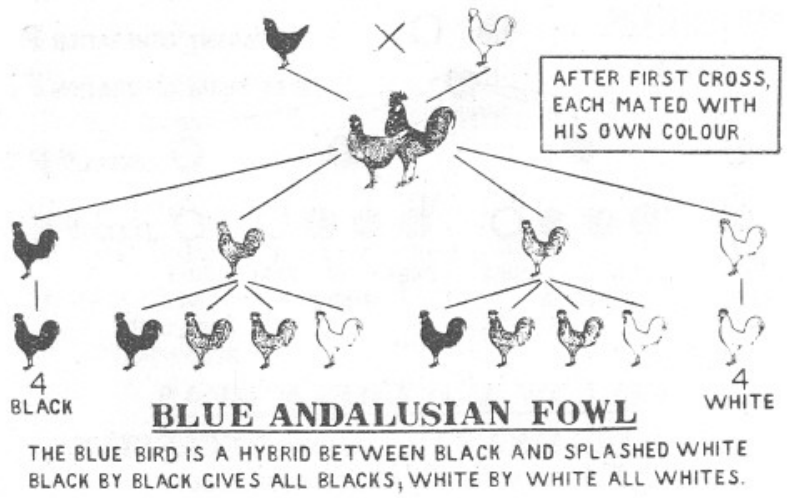

DIAGIAM 2.

blue birds bred together give blacks, blues and splashed whites in the proportions of one black, two blues, one splashed white.

When the blues of this second generation are bred together they give offspring in the same proportions: one black, two blues, one splashed white.

The diagram showing these relations should be compared with that representing the yellow and green peas. It will be seen that the scheme of inheritance is really exactly the same in the two cases, the apparent difference being due to the fact that whereas the hybrid pea takes on the character of the dominant yellow parent, the hybrid Andalusian has an appearance intermediate between the two parents.

That the yellow hybrid pea has a different constitution from its yellow parent, although its appearance is the same, is shown when hybrid plants are self-fertilised or bred together. As we have seen, the offspring are one pure yellow, two hybrid yellow, and one pure green. A further means of testing the hybrid character of this yellow pea is to fertilise the plant grown from it with pollen from a pure recessive plant grown from a green pea. Hybrid yellow crossed with green gives green and yellow peas in equal numbers.

Similarly a blue Andalusian mated with a splashed white gives blue hybrids and splashed whites in equal numbers, or a blue crossed with a black gives blues and blacks in equal numbers.

What I have described so far are the experimental facts, which have been repeatedly confirmed on these and many other plants and animals, 
and can be seen for himself by anyone who will take the trouble to carry out the necessary experimental work, taking all precautions to prevent false crossings by insects or false matings.

Mendel himself experimented also on a number of other characters in peas, and found that they followed the same scheme. Tall plants were dominant to dwarfs, and when the first tall hybrids were self-fertilised they gave tall and dwarf plants in the proportion of $3: 1$. Coloured flowers were dominant to white, but the whites reappeared again in the next generation.

In order to explain his results Mendel put forward a simple theory, the correctness of which all subsequent work has tended to confirm. Before attempting to explain this theory I must ask you to regard plants and animals from a point of view somewhat different from that which we usually take-from the point of view of the race or species rather than from that of the individual life. The plant withers, the flower fades, the creature dies, but still the race continues,

\section{"So careful of the type she seems, \\ So careless of the single life."}

How is this continuity of the race preserved ? That is the fundamental question which the physiology of heredity must seek to answer. What we know is that the germ cell, the germ plasm as Weismann called it, passes on uninterruptedly from generation to generation, increasing in bulk by the absorption of nourishment, dividing and subdividing, but apparently only seldom or extremely slowly undergoing any essential modification of its structure. The permanent, essential feature for the species is this germ plasm; the body of the individual plant or animal is an elaborate but purely temporary home for its protection and nourishment. As Samuel Butler puts it in his quaint way "a hen is merely an egg's way of producing another egg." "The germ plasm, according to this view," says Darbishire "is immortal; the excrescence, the body, is mortal."

It is in the gametes or germ cells - the ovule and the pollen of the plant and the corresponding structures of the animal-that the germ plasm is carried on. In the higher plants and animals this transmission is generally, though not always, complicated by the introduction of the phenomenon of sex, the union of the germ cells from two individuals of the species, or at least of germ cells of two different kinds.

In formulating his theory to account for the scheme of the hereditary transmission of characters which has been described, Mendel directed his attention primarily to the germ cells. Every gamete, that is to say every ovule and every grain of pollen, must contain something by means of 
which each character of the offspring is determined. What this something is, whether a material particle, a definite chemical substance, or some special arrangement of the molecules, we have no idea. For want of a better name it is usual to call it a "factor." Thus we should say that each ovule and each pollen grain of the green pea contains a "factor" for green colour ; each ovule and each pollen grain of the pure yellow pea contains a "factor" for yellow colour. When he had to deal with two alternative characters in a plant, such as green and yellow colour, Mendel assumed that any particular gamete was able to contain the factor for only one of these characters. In the same gamete the two characters are mutually exclusive. Each gamete must be pure for one or other of the factors. In the zygote, the individual produced by the union of two gametes, on the other hand, the factors for the two characters can both have place.

Let us see how this conception can be applied to the case of the yellow and green peas. In Diagram 3 the factor for yellow colour is represented

\section{YELLOW AND GREEN PEAS.}

DOMINANT CROSSED WITH RECESSIVE.
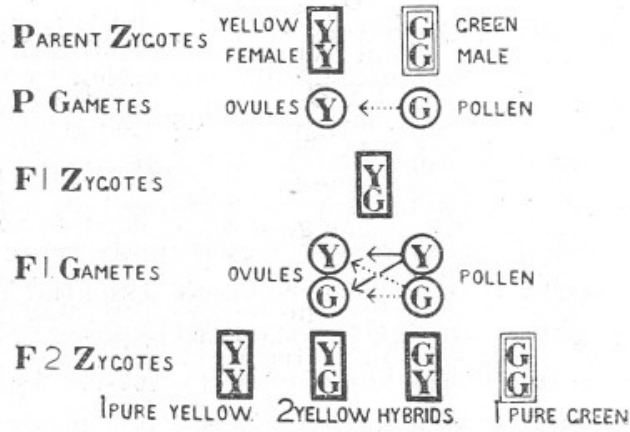

DIAgRAM 3.

by $\mathbf{Y}$, that for green colour by $\mathbf{G}$. The pure yellow peas never produce anything but yellow; we may therefore represent their constitution by $\mathbf{Y}$ , one factor having been derived from each parent. Similarly, pure

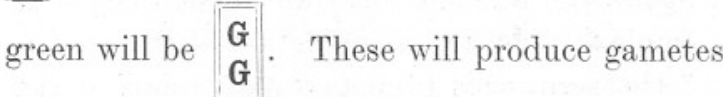

$\mathbf{Y}$ male, $\mathbf{Y}$ female, in the one case,

$\mathbf{G}$ male, $\mathbf{G}$ female, in the other, and no other kinds are possible.

If we cross the two, the only possible combination is $\left[\begin{array}{l}\mathbf{Y} \\ \mathbf{G}\end{array}\right]$, which will represent the constitution of the 1st Hybrid generation. What Mendel's 
theory lays down is that when gametes are formed by these hybrids with the constitution $\left[\begin{array}{l}\mathbf{Y} \\ \mathbf{G}\end{array}\right]$, only one of the factors can enter into the same gamete, so that we have gametes of two kinds, the first containing the $\mathbf{Y}$ factor only, the second containing the $\mathbf{G}$ factor only.

If the gametes from a male and a female individual of these hybrids are now allowed to unite together they can do so in four different ways, and in four ways only. Amongst a large number coming together by chance equal numbers of each combination will result.

The combinations are :-

$\mathbf{Y}$ male with $\mathbf{Y}$ female, gives $\left|\begin{array}{l}\overline{\mathbf{Y}} \\ \mathbf{Y}\end{array}\right|$ original pure yellow pea.

$\mathbf{Y}, \quad, \mathbf{G},, \quad, \quad \overline{\mathbf{Y}}$ yellow pea, because yellow is dominant to green, but hybrid in constitution.

$\mathbf{G} \quad, \quad, \quad \mathbf{Y} \quad, \quad, \quad\left[\begin{array}{l}\mathbf{G} \\ \mathbf{Y}\end{array}\right.$ ditto.

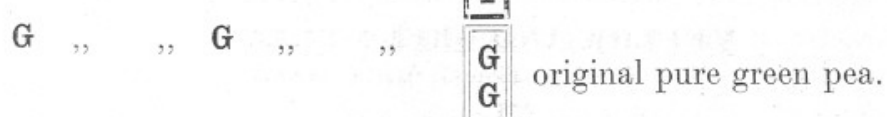

We have therefore in the second hybrid generation (F.2.)
1 Y Y
$2 \mathrm{Y} \mathrm{G}$
$1 \mathrm{G} \mathrm{G}$

that is 1 pure yellow, 2 hybrid yellow, 1 pure green.

This result agrees exactly with the facts as determined by experiment. Mendel's theory of the purity of the gametes is, therefore, in this case in complete accord with the facts.

We may test it further by seeing the result of crossing a hybrid yellow pea with a pure green pea, as illustrated in Diagram 4.

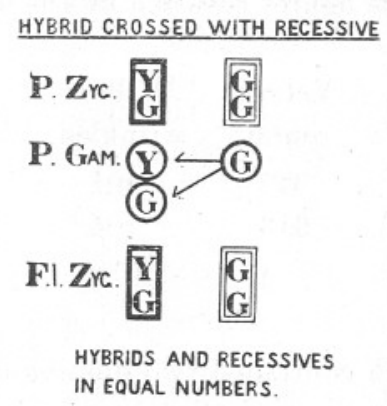

Diagram 4.

The hybrid yellow contains the factors for both yellow and green, its constitution being $\left|\begin{array}{l}\mathbf{Y} \\ \mathbf{G}\end{array}\right|$, and it produces gametes $\mathbf{Y}$ and $\mathbf{G}$ in equal numbers. 


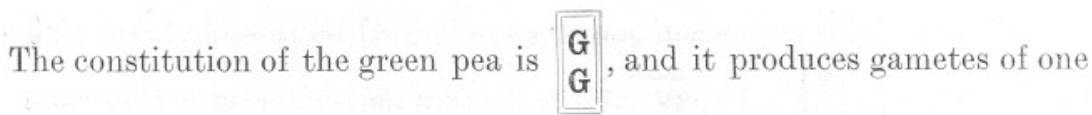
kind only, namely $\mathbf{G}$. If we unite equal numbers of $\mathbf{Y}$ and $\mathbf{G}$ with $\mathbf{G}$ only,

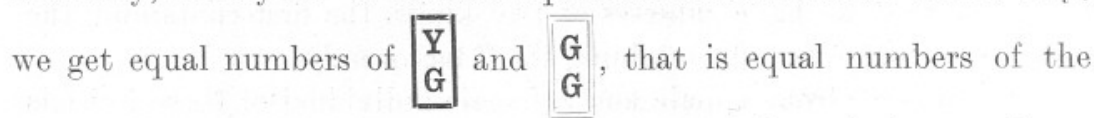
yellow hybrid and of the pure green. This result is again in accordance with experiment.

So far we have considered in each case only one pair of alternative characters. There are of course often a number of such pairs existing at the same time, each pair of which behaves in accordance with Mendel's law. This gives us a result which perhaps appears at first sight to be more complex than it really is. Diagram 5 (p. 364) represents a case studied by Mendel in peas, in which two pairs of characters are involved. First we have the two colours, yellow and green, which have already been considered. At the same time, some of the peas are round in shape, whilst others are very much wrinkled, the wrinkling being really dependent upon the character of the starch grains which constitute the bulk of the pea. In the diagram yellow is represented by a broad black line, green by a broad white line, wrinkled by a broken line.

If we cross-fertilise flowers from a plant bearing pure yellow, wrinkled peas with those of one bearing green round ones, we get in the first hybrid generation yellow round peas. Yellow is dominant to green, as we already know, and round is dominant to wrinkled, which is recessive.

Plants grown from such double hybrid peas were allowed to selffertilise and four kinds of peas were produced: yellow round, yellow wrinkled, green round, and green wrinkled. Mendel's figures for this cross are shown below, the figures required by theory being placed underneath them :-

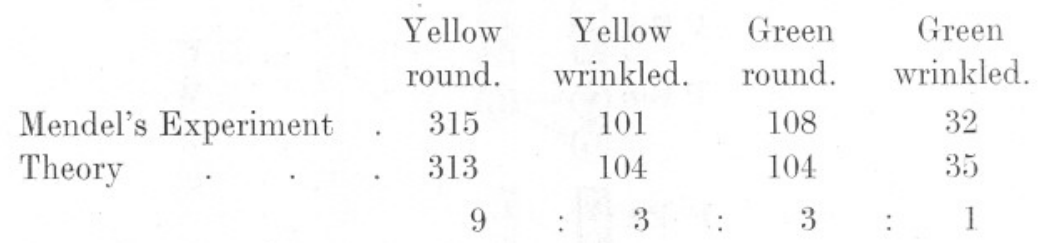

The combination which contained two dominants, yellow and round, was most numerously represented, that containing two recessives, green and wrinkled, was least numerous.

The theoretical analysis of the case is as follows :-

Let $\mathbf{Y}=$ yellow, $\mathbf{G}=$ green, $\mathbf{R}=$ round, $\mathbf{W}=$ wrinkled. 
The constitution of the original parents will be

\begin{tabular}{|c|c|}
\hline $\begin{array}{l}\mathrm{Y} \\
\mathrm{Y} \\
\mathrm{Y}\end{array}$ & $\begin{array}{l}\text { G R } \\
G R\end{array}$ \\
\hline $\begin{array}{c}\text { Yellow } \\
\text { wrinkled. }\end{array}$ & $\begin{array}{l}\text { Green } \\
\text { round. }\end{array}$ \\
\hline
\end{tabular}

Gametes :- $\quad$ Y W. $\quad$ G R.

The Hybrid must therefore be

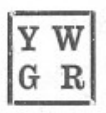

The Gametes from this hybrid are :-

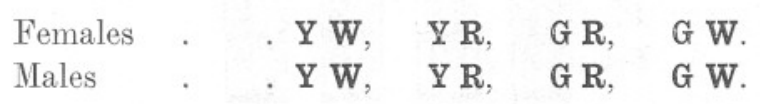

The second (F.2.) generation will therefore give (see Diagram 5) :-

$\begin{array}{cccc}\text { Y W } & \text { Y R } & \text { G R } & \text { G W } \\ \text { Y W } & \text { Y W } & \text { Y W } & \text { Y W } \\ \text { Yellow } & \text { Yellow } & \text { Yellow } & \text { Yellow } \\ \text { wrinkled. } & \text { round. } & \text { round. } & \text { wrinkled. } \\ \text { Y W } & \text { Y R } & \text { G R } & \text { G W } \\ \text { Y R } & \text { Y R } & \text { Y R } & \text { Y R } \\ \text { Yellow } & \text { Yellow } & \text { Yellow } & \text { Yellow } \\ \text { round. } & \text { round. } & \text { round. } & \text { round. } \\ \text { Y W } & \text { Y R } & \text { G R } & \text { G W } \\ \text { G R } & \text { G R } & \text { G R } & \text { G R } \\ \text { Yellow } & \text { Yellow } & \text { Green } & \text { Green } \\ \text { round. } & \text { round. } & \text { round. } & \text { round. } \\ & & & \text { G } \\ \text { Y W } & \text { Y R } & \text { G } & \text { G W } \\ \text { G W } & \text { G W } & \text { G W } & \text { G W } \\ \text { Yellow } & \text { Yellow } & \text { Green } & \text { Green } \\ \text { wrinkled. } & \text { round. } & \text { round. } & \text { wrinkled. }\end{array}$

'That is 9 Yellow round, 3 Yellow wrinkled.

3 Green round, 1 Green wrinkled.

It will be seen by an examination of Diagram 5 that the yellow rounds of the second hybrid generation have not all the same constitution. Some of them carry a factor for green, which being recessive does not appear in the visible result of the experiment; some carry a factor for 
wrinkled, which also is recessive. That these factors are actually present can be proved by continuing the experiment to the next generation. Similarly the yellow wrinkled and the green rounds are not all the same.

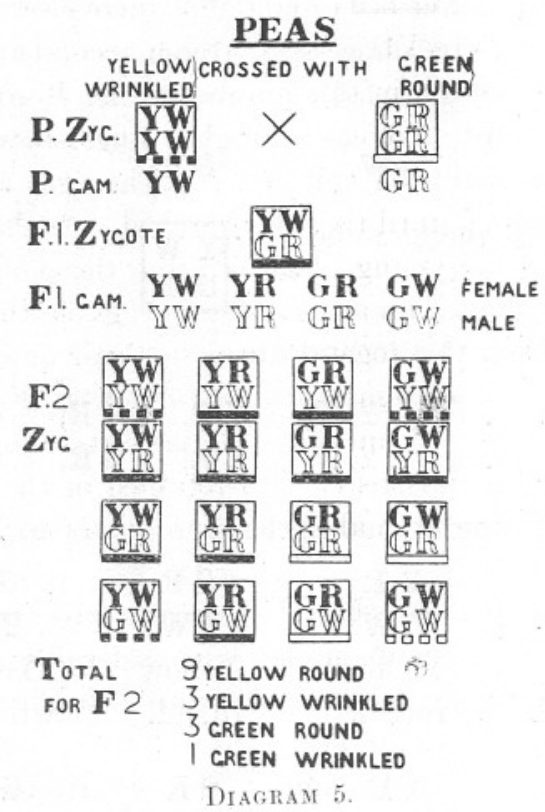

In the case of the green wrinkled, on the other hand the double recessive - one constitution only occurs, and these peas would all breed true for however many generations the breeding were continued.

From what has been said already you will I hope have got a clear idea of the simple law, first enunciated by Mendel, which often governs the hereditary transmission of characters from parent to offspring. I propose now to communicate to you some results of the study of a particular instance of Mendelian inheritance, which has been worked out during the last two or three years in connection with the Marine Biological Laboratory. One paper, describing the earlier portions of the work, has been published already in the Journal of the Marine Biological Association, bearing the title "Experiments on the Mendelian Inheritance of Eyecolour in the Amphipod Gammarus chevreuxi, by E. W. Sexton and M. B. Wing." I have now in preparation a further paper (see page 273 of this Journal) dealing with the later investigations, the experimental work eonnected with which has been carried out by Mrs. Sexton.**

\footnotetext{
* SExpos, E. W., and Wrsg, M. B. Experiments on the Mendelian Inheritance of Eyecolour in the Amphipod Gammares cherverxi. Journ. Mar. Biol. Assoe, XI, p. 18. 1916. Allen, E. J., and SExtos, E. W. The Loss of the Eye-pigment in Gammarus: chevereri. Journ. Mar. Biol. Assoc., XI, p. 273. 1917.
} 
Gammarus chevreuxi is a small shrimp-like animal, belonging to the Crustacean order, Amphipoda. It is about $\frac{1}{2}$ inch long, and lives in great abundance in the brackish-water ditches at Chelson Meadow, just above Laira Bridge. It has never been found anywhere else. A drawing of the animal is shown on Plate VII, Fig. 1, which accompanies the preceding paper by Allen and Sexton in this number of the Journal.

The animals are kept alive easily in glass finger-bowls and feed freely on dead leaves, especially on elm leaves. The eggs are carried by the female in a brood pouch until they are hatched. As soon as one batch of eggs is hatched and the young liberated from the pouch, another batch is laid. A batch may contain as many as $50 \mathrm{eggs}$, so that a large number of young can be obtained altogether from one pair of animals. The eggs take 14 days to hatch at a temperature of about $60^{\circ} \mathrm{F}$. The young grow rapidly and reach maturity in about 36 days at summer temperatures. Hence from 5 to 6 generations can be obtained in the course of a year, a fact which makes the animal specially suitable for the study of the problems of heredity.

The eye of Gammarus, like that of all crustaceans and insects, is of the compound type. It is made up of a considerable number of single elements, the ommatidia, each provided with a simple lens and receiving a nerve-fibre from the optic nerve.

In the normal animal each ommatidium is surrounded by 5 pigment cells, which lie deeply in the tissue of the eye, and are filled with pigment of a jet-black colour. Just below the surface of the cuticle or skin and surrounding the black pigment there is a quantity of milk-white or rather chalk-white pigment. This gives the whole eye, when looked at directly in the living animal, a honeycombed appearance, the white pigment forming a kind of network in which the round, black ommatidia are enmeshed. (See Plate VII, Fig. 2, of preceding paper.)

Whilst the habits and development of this animal were being studied, there appeared amongst the descendants of a pair of normal black-eyed Gammarus brought in from Chelson Meadow in June, 1912, in the third generation, that is amongst the grandchildren, a small number of young ones which had bright red eyes. The usual black pigment was replaced by red pigment, the network of chalk-white remaining as in the ordinary eyes. (Plate VII, Fig. 3, of preceding paper.) From this family a race of red-eyed animals was established, which has been used in these experiments. It is only in this one family that red eyes have ever appeared, and although very many thousands of specimens from the natural habitat have been examined, and many thousands more have been bred from pure black-eyed parents, no other case of the sudden appearance of a red eye has been met with. 
Sudden and unexpected changes in a character of a pure race have been known by naturalists, as well as by practical breeders, to occur from time to time in both animals and plants, and are called in popular language "sports." Sometimes, no doubt, these sports are due to the reappearance of a latent or hidden character, which existed in the ancestry of the organism; at other times the so-called sports may be due to a sudden change in the constitution of the individual or of the germ cell from which it sprang, so that the character may be said to originate in the particular individual, instead of being inherited from its ancestors. To new characters which originate suddenly in this way the name mutation has been given. The red eye of Gammarus may be described as a mutation, appearing in the third generation of a wild animal which had been subjected to the artificial conditions of captivity.

The red-eye is transmitted from parent to offspring, and it behaves quite in a typical Mendelian way, red eye-colour being recessive (like the green pea), and black eye-colour dominant (like the yellow pea). For use in the hybridisation experiments a pure black stock, obtained from Chelson, was kept and thoroughly tested. The stock was maintained for over three years, the offspring and descendants being all examined at different seasons of the year, and in no single case has one with red eyes been found amongst them. Numbers of pairs of red-eyed animals, also, have been bred together, each pair being kept in a separate vessel. The young have all been examined for eye-colour, and the experiment has been continued to the fifth generation and beyond, well over a thousand young having been recorded. A black-eyed animal was never once found amongst them. Both the wild, black-eyed Gammarus, therefore, and the red-eyed variety, which arose in the Laboratory, breed perfectly true to type.

Red-eyed animals were mated with pure black, the cross being made in both ways, red female with black male, black female with red male. In the early experiments 3,779 young ones were examined and recorded. Without exception the eyes were black. Clearly, therefore, black is dominant and red recessive.

The black-eyed hybrids obtained from the cross between black and red were mated together. They produced altogether 4,393 young, of which 3,327 were black-eyed and 1,066 were red-eyed. (See Diagram 6.1.) This is a very close approximation to the $3: 1$ ratio. There are 32 reds too few on a total of 1,066 reds. This may be due merely to chance, or it may be due to the fact ascertained during the course of the experiments that the red-eyed animals are not quite as vigorous and healthy as the black-eyed. The deficiency in the number of reds may therefore mean that more red than black failed to survive whilst the eggs were developing in the brood-pouch of the mother. 
HEREDITY IN PLANTS, ANIMALS, AND MAN.

1. BLACK CARRYING RED $\times$ BLACK CARRYING RED.

$\begin{array}{lrrr} & & \text { Blacks. } & \text { Red. } \\ \text { Experiment } & 3,327 & & 1,066 \\ \text { Theory } & \cdot & 3,294 & 1,098 \\ & & 3 & 1\end{array}$

2. BLACK CARRYING RED $\times$ RED.

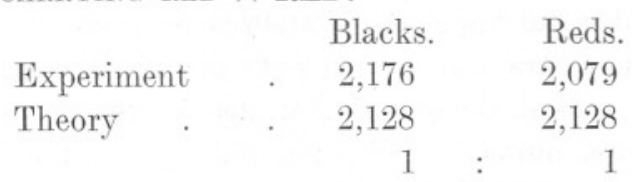

3. BLACK CARRYING RED AND ALBINO $\times$ BLACK CARRYING ALBINO.

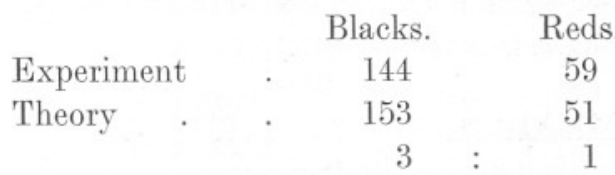

4. BLACK CARRYING RED AND ALBINO $\times$ RED CARRYING ALBINO.

$\begin{array}{lrrrrr} & & \text { Blacks. } & \text { Reds. } & \text { Albinos. } \\ \text { Experiment } & . & 235 & & 169 & 144 \\ \text { Theory } & . & 205 & & 205 & \\ & & 3 & : & 3 & :\end{array}$

5. BLACK CARRYING RED AND ALBINO $\times$ BLACK CARRYING RED AND ALBINO.

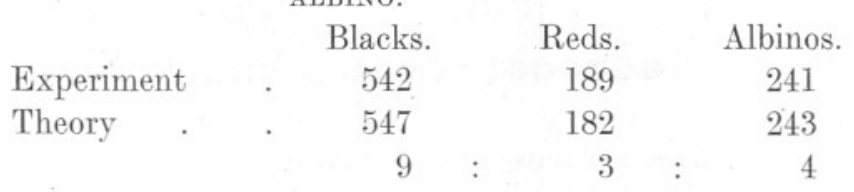

6. RED CARRYING ALBINO $\times$ RED CARRYING ALBINo.

$\begin{array}{lrr} & \text { Reds. } & \text { Albinos. } \\ \text { Experiment } & 1,408 & 471 \\ \text { Theory } & 1,409 & 470 \\ & 3 & : \\ & \text { Diagram } 6 . & \end{array}$

Eye-colour of Gammarus. Results of various crosses.

Hybrid blacks were mated with red-eyed recessive animals. (Diagram 6. 2.) 4,255 young were obtained and examined as soon as extruded from the brood-pouch. 2,176 were black-eyed, and 2,079 were red-eyed, which is very close to the equality which Mendel's theory demands. There is again a slight deficiency of red-eyes, namely 49.

This cross of the hybrid with the recessive, which we have already studied in the yellow and green peas, is a specially important one to any- 
one investigating problems of inheritance, because its result enables us to distinguish the pure dominant from the hybrid which in appearance resembles it. We have seen that the pure black mated with red gives all black oftspring. If, therefore, when a black and a red are mated together we get some red-eyes amongst the children, we know that it is a hybrid black that we are dealing with.

One other mating of these two varieties remains to be considered. When hybrid blacks are mated with pure blacks, the dominant asserts itself completely, and all the offspring are black-eyed. The total number of young obtained in our earlier experiments from crosses of this kind was 379 - all with black eyes.

In one family, belonging to the first generation of hybrids got by crossing the red-eyed Gammarus with the pure black-eyed one, a second sport

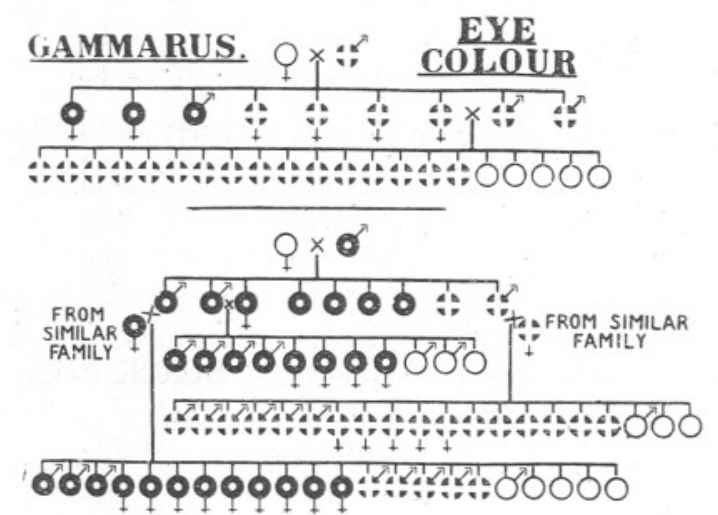

Diagram 7 .

A Black dise with white centre represents a black-eyed animal.

A Black dise with white cross represents a red-eyed animal.

A Black ring represents an albino-eyed animal.

$$
\delta=\text { male. } \quad q=\text { female. }
$$

or mutation appeared. The brood in which this mutation occurred consisted of 7 black-eyed young, 1 red-eyed and 4 in which neither black nor red pigment could be seen, and only the network of chalk-white pigment was left. (Plate VII, Fig. 4, of preceding paper.) The eye was also very irregular in shape and altogether of a degenerate character, the number of ommatidia being very few. These degenerate eyes, with only white pigment, we shall speak of as "albino" eyes.

In order to determine the constitution of these degenerate albino eyes, and to find out whether or not the condition was hereditary, one of the animals, a female, was mated first with a pure red male, and then with a known hybrid black one.

The result of these matings is shown on Diagram 7, and will probably 
surprise you. Albino-eyed female mated with pure red-eyed male gave 6 red-eyed and 3 black-eyed young. Albino-eyed female mated with hybrid black gave in four broods 75 black-eyed and 15 red-eyed young.*

In the grandchildren from both crosses, however, you will see that the albino-eyed form reappears.

From this it follows :-

(1) that the factor for albino eye is transmitted from parent to offspring, but that colour is dominant and albino recessive, for when albino is mated with coloured eye no albinos occur in the first generation of offspring ;

(2) that the original albino-eyed female must have contained the factor for black, since black offspring were produced when it was mated with pure red, which we know from the previous work contains no black ;

(3) that the albino-eyed female must contain the factor for red, and this for two reasons: in the first place, if it had contained black only we should have got only black offspring when it was mated with red, for we know that black is dominant to red; in the second place, and again because black is dominant to red, if the albino had contained black only, when mated with the black hybrid we should have had only black offspring, whereas we obtained 75 blackeyed and 15 red-eyed. We know that when the hybrid, containing red and black, is mated with another hybrid of the same kind the resulting offspring should be 3 black to 1 red.

We must now look more closely at the grandchildren of the original albino-eyed female, which were all obtained by mating together her immediate offspring of the F.1 generation. When two blacks were mated together in F.1 two kinds of broods resulted, some in which only black and albino-eyed young occurred, others in which black, red, and albino were present. When two F.1 reds were mated together the broods contained red-eyed and albino-eyed young. (See Diagram 7.)

This resembles closely what is found in coat colour in animals such as rabbits, mice, and rats, which has been worked out by Bateson, Punnett, and others. To explain the phenomena these authors assume that in order that the colour in the coat of an animal may be visible it is necessary that at least two factors should be present, one factor representing the colour itself - say black or brown, as the case may be and a second factor which must be present in order that the colour may show itself. In the absence of this latter factor, which they call the colour factor, the

* In the diagram one brood only is shown from this mating, consisting of 7 black-eyed and 2 red-eyed young.

NEW SERIEs, - voL, XI. No. 3. DECEMBER, 1917. 
animal will be white, though it may still retain the power of transmitting a particular colour to its offspring. The black or brown factor is present in the animal's constitution, but in the absence of the colour factor the black or brown does not appear.

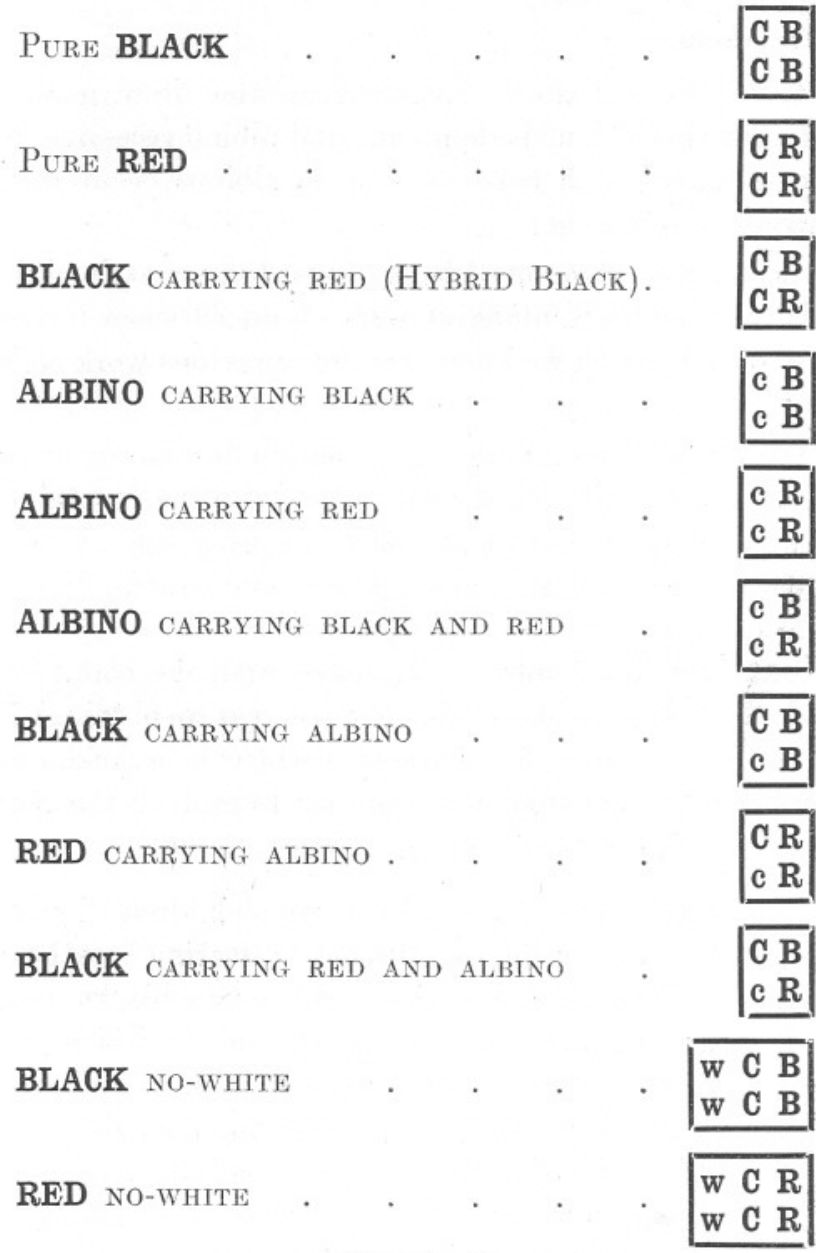

DIAGRAM 8 .

Eye-colour of Gammarus. Constitutions of some of the different kinds.

C represents the factor for colour, c the alsence of this factor.

$\mathbf{B}$ represents the factor for black, $\mathbf{R}$ that for ret.

w represents the factor for absence of white pigment.

Animals of the first nine constitutions shown on the diagram all possess the white pigment, and this might have been indieated by adding $\underset{\mathbf{W}}{\mathbf{W}}$ to the formula in each case.

A similar hypothesis will explain the present case. Diagram 8 shows the constitutions on this hypothesis of some of the varieties of Gammarus 
which have been obtained in the experiments. The colour factor is indicated by $\mathbf{C}$, the absence of this factor by c. $\quad \mathbf{C}$ is dominant to $\mathbf{c}$. $\mathbf{B}$ and $\mathbf{R}$ represent the factors for black and red-eye respectively.

Just as we worked out on Mendel's theory the result to be expected from the crossing of yellow-wrinkled and green-round peas, so in this case we can work out the result from mating together animals with any two of these various constitutions. This has been done for all possible combinations, and the results of the experiments are in good agreement with theoretical expectations, as may be seen from a study of Diagram 6, which gives the numbers actually obtained from several of these matings, as well as those which the theory requires.

The black-eyed children of the original albino-eyed female mated to the hybrid male, all of which carry the factor for albino, or, to put it more accurately, lack one colour factor, can be crossed in three different ways :-

(1) Pure black $\times$ Pure black.

(2) Pure black $\times$ Hybrid black (Black carrying red).

(3) Hybrid black $\times$ Hybrid black.

If we work out the theory for these crosses, just as we worked it out for the peas, we find that altogether amongst the offspring, that is amongst the grandchildren of the original parents, there will be animals of nine different constitutions of eye-colour (compare Diagram 8), namely :-

4 kinds of black-eyed animals . Pure black.

Black carrying albino.

Black carrying red.

Black carrying both red and albino.

2 kinds of red-eyed animals . . Pure red.

Red carrying albino.

3 kinds of albino-eyed animals. Albino carrying black.

Albino carrying red.

Albino carrying black and red.

In the actual experiments we have been able to prove that animals of all these nine kinds occur, and the numbers also in which they are found are in sufficiently good agreement with the theoretical expectation to satisfy us of the correctness of the theory.

In Diagram 9 the actual results of a number of matings in which the albinos take part are shown, as these results are specially interesting. 
Mated together the albinos give all albino offspring, whatever their constitution, since neither parent contains the colour factor, which we have indicated by great $\mathbf{C}$, which enables the colour to appear.

\section{GAMMARUS. ALBINO $\sigma^{\prime} \times \widehat{T}_{\text {ALBINO }}$ EYE COLOUR

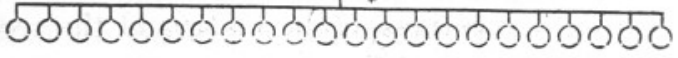 \\ ALBINO CARRYING, BLACK

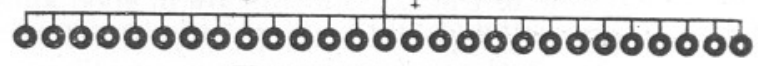

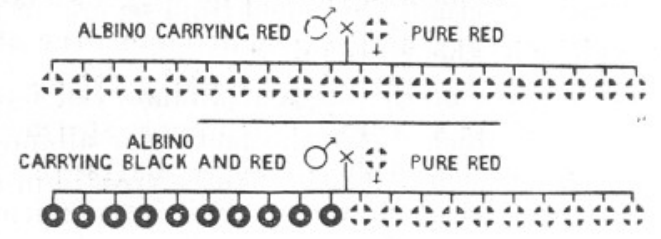

Diagliam 9.

(Signs as in Diagram 7. )

Mated with pure red, albinos give three kinds of broods :-

(1) All black-eyed young. In this case the albino contains the factor for pure black, which is dominant to red.

(2) All red-eyed young. In this case the albino contains pure red.

(3) Black-eyed and red-eyed young in equal numbers. The albino is then hybrid as regards colour, containing factors for both black and red.

There is still another sport or mutation which has occurred in the eye of Gammarus. This is the entire absence of the chalk-white pigment which lies near the surface between the ommatidia. (Plate VII, Fig. 5, of preceding paper.) These we call " no-white" eyes.

Animals with eyes like this may be either black-eyed or red-eyed, and the black-eyed ones may be either pure black or hybrid black containing red. By cross-breeding we have obtained all three kinds.

The character "no-white" is transmitted to the offspring in strict accordance with Mendel's law, the presence of white pigment being dominant and its absence recessive. If an animal therefore which possesses the white pigment is mated with one which does not possess it the offispring in the first generation all have the white pigment - their eyes are quite normal. If males and females of this first generation are mated together, in their offspring in the grandchildren of the original pair"no-whites" reappear. 
At this stage of the investigation a very interesting question arose. What would be the result of crossing the "no-whites " with albinos, and mating together their offspring ?

We may represent the factor for white pigment by $\mathbf{W}$, and its absence by $\mathbf{w}$. These two factors behave as an alternative pair, according to Mendel's law. The constitutions of the black and the red "no-whites" will then be $\begin{aligned} & \text { w C B } \\ & \text { w C B }\end{aligned}$ and $\begin{aligned} & \text { w C R } \\ & \text { w C R }\end{aligned}$

If we cross these with albinos and work out the theory, as in the case of the peas, we find that in the first generation we get all normal-eyed offspring, the "no-whites" provide the colour factor, the albinos provide the white.

The result of such a cross obtained in an actual experiment is shown in the Diagram 9 (the second brood shown on the diagram). The young are all normal-eyed blacks. They, however, differ in constitution from any black-eyed animals previously obtained, for they carry not only the factors for black and red but also the factors for both "albino" and "no-white," and are capable of transmitting all four factors to their children.

When these animals are mated together, according to the theory, which we can work out in the usual way, there should be, out of every 64 offspring, 48 with white pigment present, and 16 with no white pigment. Of these 16 with no white pigment 4 should be ALso ALBINo, that is to say they should, according to the theory, show neither white, nor black, nor red pigment. The eyes should be quite colourless.

Animals with quite colourless eyes we had never seen when the theory for this cross was first worked out. Would they be produced when an actual experiment was made? A pair of these black-eyed hybrids was mated. The first brood hatched was a small one, but our pleasure was naturally great when we found that it consisted of 2 with normal black eyes, 1 black with nơ white, and 2 quite colourless, with no eye-pigment visible at all. Since then other broods have been obtained, and there is no doubt that the facts agree with the theoretical analysis.

Looked at from a general point of view the cross of the "no-white" with the albino-eye is of great interest, and is particularly instructive. We here took the two most degenerate and abnormal types of eye that were known, and mated together the animals which carried them. In the first generation the offspring have all perfectly normal characters and are indistinguishable, as far as their own visible structures are concerned, from the perfect wild creatures. The factors lacking in one parent were supplied by the other parent and perfect children resulted. The 
defects, however, persist in a latent condition in the germ plasm of these children, and if they are mated with those of like constitution the defective characters all reappear in the grandchildren. The factors may even combine in such a way that some of these grandchildren are more defective than the defective ancestors from which they sprang. They unite the defects which were borne separately by the two grandparents. This no doubt explains some of the ill-effects which result from too close inbreeding. We should remember, too, that if here defects have been united, in other cases it would be equally possible that the excellences of different ancestors should be combined in some of their descendants.

With Gammarus, however, what we have actually observed has been a degeneration of the eye, taking place step by step as one factor after another has been lost. Bateson, in his presidential address to the British Association in Australia in 1914, emphasised the fact that most, though perhaps not all, the Mendelian cases studied up to the present can be explained rather by the loss of factors than by the introduction of new factors. Since that address was delivered there has been, shall we say, in the air - for no one has ventured, I believe, to declare himself a complete adherent to it - a theory of a kind of inverted evolution, starting with a highly complex primitive protoplasm or germ plasm, which by the loss of factor after factor has given rise to the endless varieties of plants and animals that we know. These factors are conceived of as being for the most part restraining or inhibiting factors, whose loss, one by one, in the course of ages has allowed the full powers and glories hidden in the primitive plasm to unfold themselves - a process which still goes on. What the final excellence or final catastrophe is to be, when all the bonds are broken and all the restraints are lost, no one, as far as I know, has ventured to suggest. When, however, we take into consideration the whole range of facts upon which our conceptions of organic evolution are based we find little to support such a view.

The cases of Mendelian inheritance which I have so far discussed have been of a simple character, following exactly the law which Mendel first laid down. Sometimes, however, the phenomena are more complicated. We saw that the albino-eye of Gammarus was always imperfect in shape. Absence of colour and imperfect form are here always united and remain united in inheritance. Characters which behave in this way are spoken of as linked characters, and the factors in the germ cells from which they originate are also said to be linked. There is often also a special connection between a particular character and the sex of the animals which transmit and inherit it. This is known as sex-linkage and is well illus- 
trated by eye-colour in the American fruit fly Drosophila. The wild fly has red eyes, and a sport or mutant is known which has white eyes. If a white-eyed male is mated with a red-eyed female all the offspring are redeyed, and males and females occur in equal numbers. When these hybrids are mated together there result three red-eyed flies and one with white eyes - the usual Mendelian proportions. The white-eyed flies, however, in this generation are all males, like the grandfather. If however we make the original cross in the opposite way, mating a red-eyed male with a white-eyed female a different result is obtained. Instead of having all red-eyed children, males and females in equal numbers, we have equal numbers of white-eyed males and red-eyed females. In the next generation also the result is different, for when one of these red-eyed females is mated with a white-eyed male the offspring are red-eyed females, redeyed males, white-eyed females and white-eyed males in equal numbers. It would carry us too far were I to attempt to give the explanation which has been put forward to account for this, so I shall content myself with stating the facts to show that the simple Mendelian law may at times seem to give highly complex results.

That knowledge gained by Mendelian investigations may be of great value to practical agriculture is shown by Prof. Biffen's work on the varieties of wheat. The wheats usually grown in England produce heavy crops, but the flour obtained from them is not satisfaretory from a baker's point of view. A loaf made from this flour does not rise well when baked. In order to correct this it is usual to mix the English flour with flour from a so-called " hard " foreign wheat, which contains a larger proportion of gluten. English wheats, also, are very liable to a disease known as " rust," which is caused by the growth of a fungus on the plants. Prof. Biffen was able to show that good cropping power, hardness, and ability to resist rust are all characters which behave in a Mendelian way. By a long series of experiments in crossing different varieties of wheat he was able to produce a variety which possessed good cropping powers, the hard qualities of foreign wheat, and also a complete power of resisting rust. This wheat can be grown quite successfully in the English climate, and it has kept its special qualities unchanged for a number of years.

And now for a few minutes we will direct our attention to the question in connection with this subject of Mendelian heredity, which is perhaps of more interest to us than any other. In the human race does inheritance take place in accordance with Mendel's law ? There is considerable evidence that certain characters do follow this law and that the same thing is true of certain diseased conditions.

The inheritance of eye-colour is a striking instance, which was investi- 
gated in this country by Hurst and in America by Davenport. Hurst examined the eyes of children in a Leicestershire village, and also the eyes of their parents and grandparents, where that was possible.

The iris, the part of the eye in which the colour is situated, owes its colour to two separate layers of pigment, a deep-seated layer which gives the effect of blue, and a layer near the surface which contains yellow and brown pigment. When the brown pigment of the surface layer is fully developed it hides completely the blue underneath it, and the eyes are dark brown in colour. If the brown pigment is entirely absent we get the true blue eye, and such an eye Hurst calls simplex. Eyes with both blue and brown pigment he calls duplex, and these duplex eyes are of two

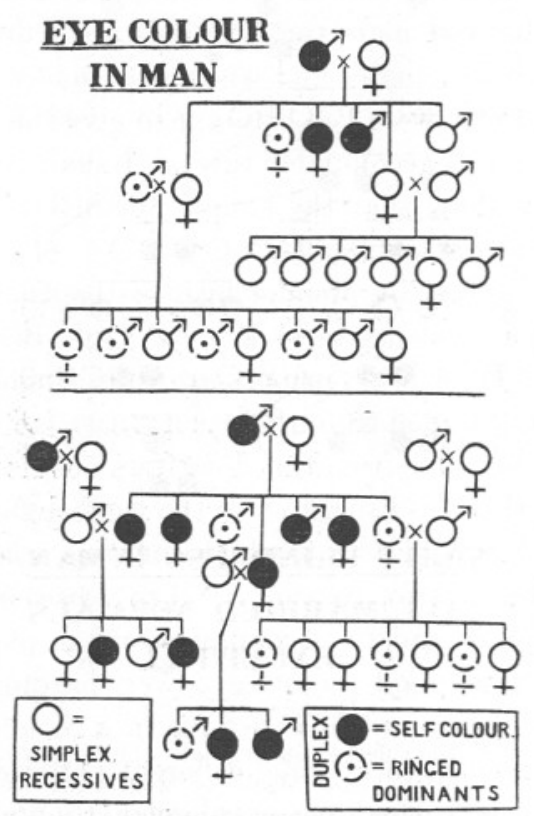

DIAGRAM 10 .

kinds. First, those in which the brown completely covers the iris and hides the blue, the so-called self-coloured or whole-coloured eye, and second, eyes in which the brown pigment forms a ring round the black pupil in the centre of the eye, whilst the greater part of the blue layer can still be seen. Such duplex eyes are called " ringed." The details of distribution of eye-colour in two of the families examined by Hurst are shown in Diagram 10.

These and other results which were obtained showed that whole-coloured brown eyes were always dominant to ringed and also to blue. Ringed eyes were also dominant to blue. The blue simplex eyes were pure reces- 
sives, and whenever father and mother both had such eyes all the children also had eyes of the same kind.

The dominant self-coloured and ringed eyes, on the other hand, might be either pure dominants, or hybrids containing the factor for recessive blue eyes. Several instances of these hybrids are seen in the diagram.

The next diagram (Diagram 11), which is extracted from a much larger pedigree illustrated by Bateson in his book on "Mendel's Principles of Heredity," shows a portion of the pedigree of a family living in a cluster

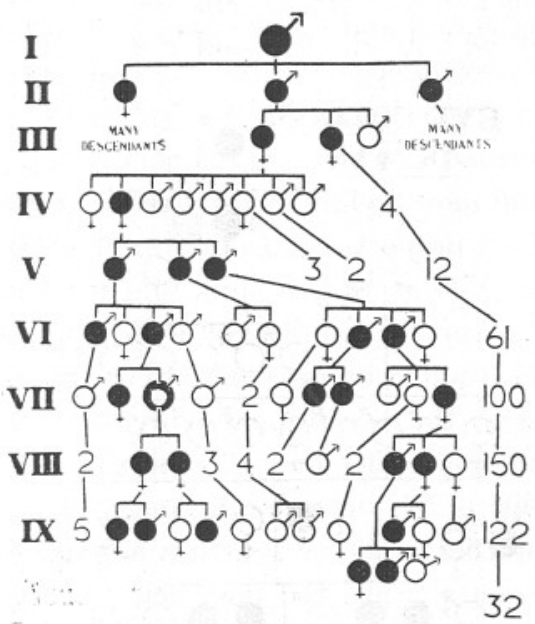

NIGHT BLINDNESS IN MAN.

ALL MARRIED NORMALS EXCEPT $\sigma$

Diagram 11.

The black discs represent the affected individuals, the rings those who did not suffer from the disease. In the exceptional case (black dise with white centre) both parents were affected. The arabic figures indicate numbers of unaffected children. Nine generations (I-IX) are illustrated.

$\delta=$ males, $q=$ females.

of villages in the south of France, in which many members have suffered from what is known as night-blindness, the affected persons being quite unable to see in a dim light. The pedigree commences with one Jean Nougaret, born in 1637, and has been followed through ten generations. In this family the disease has always behaved as a Mendelian dominant, though not a simple one, and it has always been inherited from an affected parent. Unaffected parents have never had affected descendants.

In another disease, hæmophilia, there is a curious relation with sex. 
The symptom of the disease is that the blood refuses to clot, and hence there is great loss of blood from even a very slight wound, such as a scratch. The peculiarity about its inheritance is that only the male members of a family are affected, but the disease is usually transmitted through the females, who do not themselves develop it. An apparently healthy daughter belonging to such a family will transmit the affection to her sons, and her daughters will be capable of handing it on to their children.

If we pass from a consideration of man's physical nature and ask ourselves whether and to what extent the principles we have been discussing are applicable to his moral and intellectual qualities, we enter a field of speculation of the very highest interest. In his work on "Hereditary Genius," published in 1869, Francis Galton brought together and analysed a great mass of information which proved conclusively that excellence in many intellectual and moral qualities occurred in particular families with a frequency out of all proportion to that in which it was found in the general population. No one will, I think, dispute the fact that musical ability is inherited in certain families, and the same seems to be true of mathematical genius, though by no means all the nearly related members of the families possess the exceptional powers. Galton gives a list of 36 men who took the place of senior classic at Cambridge between 1824 and 1869. In this list of 36 , the name Kennedy occurs four times, three of the men being brothers and the fourth a nephew of the others. The name Lushington occurs twice, the men being brothers, whilst a third brother was fourth classic of his year.

Mendel's law was unknown to Galton when this book was written, but a consideration of his data certainly suggests that some at least of the exceptional mental and moral attributes with which he deals may follow the general principles of inheritance which Mendel first made clear. The question is one which may well repay further investigation. And if the future should reveal to us with certainty the fundamental principles according to which human qualities, - both physical and mental, are handed on from generation to generation, shall we not have reached a real landmark in the progress of the human race towards well-being ? It is not that one contemplates direct interference with the liberty of the individual, excepting perhaps in extreme cases of physical or mental disease, but we may, I believe, look forward to a gradual incorporation in the traditions and social usages of the people, of such knowledge as shall come to stand on a certain and indisputable scientific basis. The immense power of such traditions and customs on the life of the general population cannot be denied. Gradually, too, as the new facts become firmly established, religious teachers will lend their aid, and ethical 
thinkers will submit that a high standard of morality demands that the welfare of unborn generations shall not be sacrificed. Man, it is true, is prone to follow desire rather than reason; but all these influences should not be without effect in producing a dofinite progressive improvement in the inborn qualities of the race. Such at least would seem to be the possibilities opened up by the detailed study of the laws of heredity. 